\title{
Spark location adaptive process control in meso-micro EDM
}

\author{
Umang Maradia $^{1}$ (D) - Reto Knaak ${ }^{2}$ - Walter Dal Busco ${ }^{2} \cdot$ Marco Boccadoro $^{2}$ • \\ Josef Stirnimann $^{3} \cdot$ Konrad Wegener ${ }^{1}$
}

Received: 19 January 2015 / Accepted: 13 May 2015 /Published online: 27 May 2015

(C) Springer-Verlag London 2015

\begin{abstract}
Time-synchronised high-speed imaging and electrical signal measurements are performed in near-real erosion conditions to analyse the feasibility of determining spark location based on its electrical signals in die-sinking electrical discharge machining (EDM). Using this novel research platform, a correlation between the discharge voltage and the geometric location of a discharge on an electrode has been established. Through the derived understanding, a microsecond level spark location adaptive process control has been conceptualised and demonstrated. The parameter control of each spark according to its probabilistic location on the electrode results in low wear of micro- to macroscale electrode features, higher material removal rate and higher form precision despite of electrode complexity. Reduction in the required number of electrodes achieved through the novel spark location adaptive process control increases the economic and energy efficiency of die-sinking EDM.
\end{abstract}

Keywords Electrical discharge machining (EDM) - Adaptive control $\cdot$ Precision $\cdot$ Micromachining

\section{Introduction}

In die-sinking electrical discharge machining (EDM), wear on corner and edge regions of electrodes affects the form

Umang Maradia

maradia@inspire.ethz.ch

Swiss Federal Institute of Technology, Zurich, Switzerland

Agie Charmilles SA, Losone, Switzerland

inspire AG, Zurich, Switzerland accuracy of the eroded cavities and thus the required number of electrodes to reach desired precision. However, it is a wellknown fact that volumetric wear at sharp edges, corners and needle-like microstructures is much more pronounced than for larger electrode surface areas [1]. Also, process parameters required to achieve low electrode wear and high material removal rate are dependent on the electrode projection area due to the scaling effects, as shown by [2]. Thus, applying suitable parameters depending on the geometric spark location is necessary but difficult since the distribution of discharges on electrodes is stochastic [3]. The stochastic nature of discharge locations on the electrode restricts a precise control of process parameters which are adapted according to the engaged geometric feature, unlike the deterministic tool location processes such as milling and laser ablation.

In order to adapt the process parameters according to the active surface area, a concept of constant current density EDM system capable of automatically responding to the changing machining area was developed by Inoue [4]. Furthermore, Inoue [5] devised a cutting area responsive method, whereby detecting the rate of advance of the electrode relative to the workpiece, pulse packet settings such as time duration, pause duration and pulse packet interval were optimised to achieve a constant current density in spite of changing surface areas of the tool electrode. Toshiaki [6] proposed using the interelectrode impedance to determine the electrode region and apply a suitable technology. Magara [7] proposed a method to calculate the rise time of a pulse voltage applied to the machining gap for the relaxation type generators and identify the active surface area of machining.

A detailed review on the on-line spark location detection methods using either acoustic emission or electrical signal methods has been published by Li et al. [8]. Kunieda and Takanobu [9] analysed the factors determining the discharge location in EDM through debris analysis, whereas Morimoto 

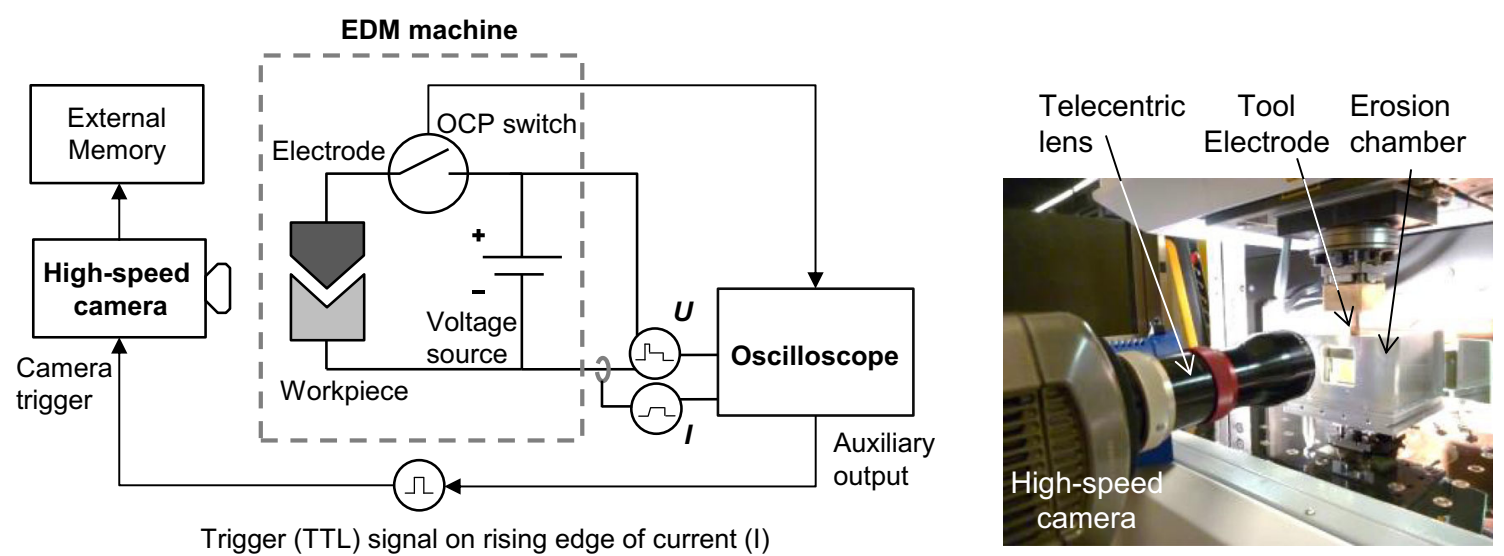

Fig. 1 Left: schematic view of the experimental setup and measurement method. Right: an erosion chamber with glass windows, mounted on an EDM machine to allow visual observation of the process

and Kunieda [10] analysed the capability to locate discharges on the electrode based on the delay time. Valentinčič and Junkar [11] proposed a model for detection of the eroding surface area based on discharge parameters using machine learning and evaluated the discharge voltage dependence on the active surface area. Based on this theory, on-line selection of rough machining parameters [12] and selection of optimal machining parameters for a given surface have been proposed in [13]. Here, the process control model is based on analysing a finite number of sparks to determine the average values and ratio of short sparks and arcs [14].

Apart from the changing surface area, lateral sparks on the electrode cause tapers instead of vertical walls. Kumagai et al. [15] developed an EDM drilling system employing a composite electrode, where a simple cylindrical electrode is encased in a dielectric jacket to prevent the lateral discharges occurring between the sidewalls of the rod electrode and the fabricated hole. Klocke et al. [16] analysed the electrode deflection for high-aspect-ratio cavity erosion, which is found to be caused due to discharge forces, especially by lateral discharges.

Recently, Okada et al. [17] evaluated the spark distribution in respect to wire vibrations in wire-EDM using high-speed imaging. Kitamura et al. [18] used an electrically conductive transparent $\mathrm{SiC}$ single crystal workpiece and copper electrodes to observe the EDM gap phenomena using a highspeed camera. Distribution of the discharge locations and volume fraction of bubbles in the working gap were analysed for the first few seconds from the erosion beginning.

It is seen that a number of techniques are developed for the discharge location determination; however, most of the adaptive control methods described above react on the time scales larger than a few milliseconds and are thus unable to react on the microsecond scale for each spark. In this work, determination of the geometric location of each spark on the electrode is performed through high-speed imaging in near-real erosion conditions during steady state conditions, a technique not found in literature so far. In EDM, electrical signals of sparks are used for various adaptive control methods or feedback control systems as shown by [19-21], such as adaptive control constraints (ACC) and adaptive control optimisations (ACO). Thus, electrical signals and the location on the electrode are correlated for the observed discharges. From the gained understanding, a novel spark location adaptive control method has been conceptualised and demonstrated.

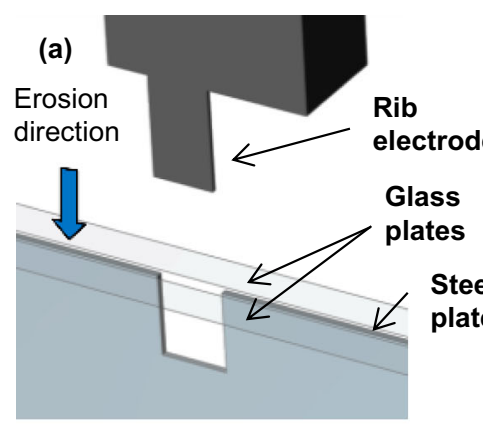

(b)

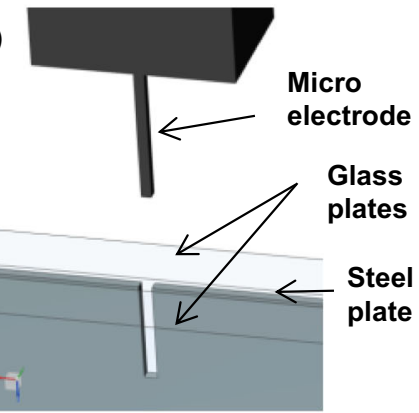

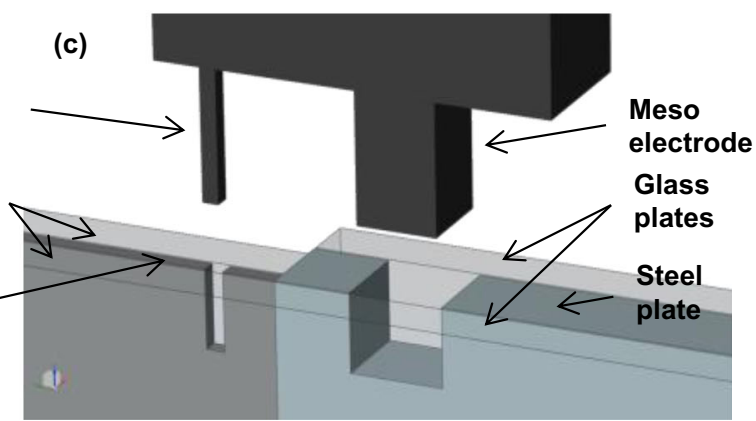

Fig. 2 Near-real erosion condition emulated by replacing two of the four metal walls of a machined cavity with glass; a micro-rib electrode, $\mathbf{b}$ microelectrode, and combination electrode with a micro- and a mesoscale feature 

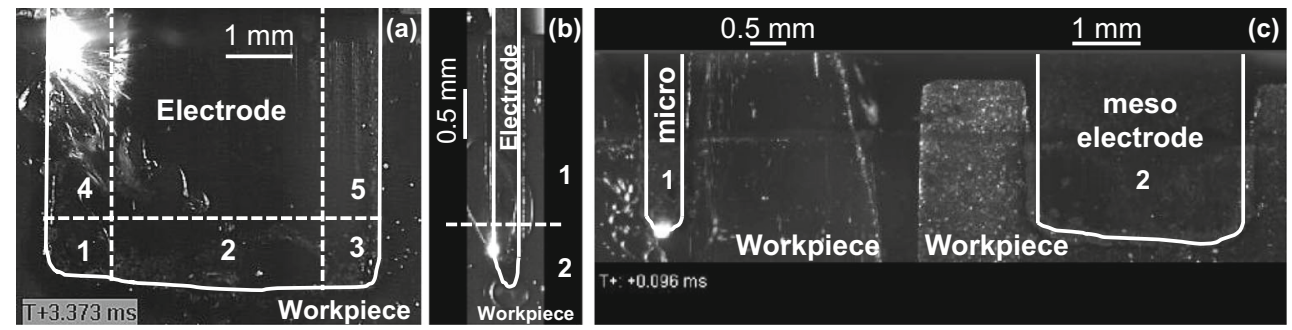

Fig. 3 Images of the different electrode configurations during near-real erosion conditions; a micro-rib electrode, $\mathbf{b}$ microelectrode, and $\mathbf{c}$ combination electrode. Different regions are defined such as corners, lateral sides, micro- and mesoscale features of a combination electrode

\section{Spark location detection}

\subsection{Experimental setup and methods}

A schematic overview of the experimental setup is shown in Fig. 1 (left). Here, a high-speed camera is used to visually observe the process, and an oscilloscope is used to acquire voltage $U$ and current $I$ signals between electrode and workpiece. In order to observe sparks during erosion, an erosion chamber is constructed with glass windows on the front and back sides as shown in Fig. 1 (right). This chamber is mounted on a commercial die-sinking EDM machine Form 1000 from Agie Charmilles SA. The erosion chamber is filled with dielectric oil IME110 from Oelheld GmbH. Poco EDM3 Graphite is used as electrode material, and the used workpiece materials are steel 1.2343 and 1.1274. The pulse duration of sparks is varied between 50 and $100 \mu$ s with the pause duration of $1000 \mu \mathrm{s}$. Using a constant current source generator, spark current ranging from 5 to $20 \mathrm{~A}$ is applied with $100 \mathrm{~V}$ positive electrode polarity. The servo control is based on the gap voltage.

Three different electrode configurations are used for the analysis, namely micro-rib, microelectrode and a combination electrode comprising a micro- and a mesoscale feature. Experiments are performed in a near-real erosion condition, where the discharge region and eroded cavity are tightly sealed between two glass plates. Thus, a near-real erosion condition is created by replacing two of the four vertical metal walls of the machined cavity by glass plates, as depicted in Fig. 2. The discharge region is externally illuminated from the front and

Table 1 High-speed camera settings for the different electrode configurations

\begin{tabular}{llll}
\hline Camera settings & Micro-rib & Micro & Combination \\
\hline Pixel region & $304 \times 160$ & $48 \times 224$ & $512 \times 152$ \\
Frames per second & 50,000 & 50,000 & 50,000 \\
Video duration & $1.8 \mathrm{~s}$ & $3.7 \mathrm{~s}$ & $1.4 \mathrm{~s}$ \\
\hline
\end{tabular}

back windows of the erosion chamber. Some acquired images for each electrode configuration are presented in Fig. 3 along with the defined regions on the electrodes, such as corners, lateral sides and frontal side.

A high-speed camera Phantom 12.1 from Vision Research equipped with a telecentric lens $(\times 1$ magnification $)$ is used for imaging. The duration of a recorded video depends on the memory capacity of the camera, which is 8.4 GB. Table 1 shows the main parameters applied for the high-speed camera and acquired video durations for the different electrode configurations. Images are acquired at an interval of $20 \mu$ s with an exposure time of $19 \mu \mathrm{s}$. Thus, using 50,000 frames per second (fps) setting, five images are acquired of a spark with pulse duration of $100 \mu \mathrm{s}$.

A Lecroy 44Mxi oscilloscope is used for the measurement of electrical signals. The oscilloscope time resolution is set at $500 \mathrm{~ns}$ to record $5 \mathrm{~s}$ of voltage and current signal data in a single shot. The oscilloscope trigger is set on a rising edge of the current signal. Here, the single-shot acquisition is activated manually, following which the first current signal of a spark triggers the voltage and current signal acquisition for the duration of $5 \mathrm{~s}$. Upon detecting the trigger, the oscilloscope sends a $5 \mathrm{~V}$ signal to the camera, which triggers the recording of a high-speed video. The delay between the trigger and the image acquisition is in the scale of a few nanoseconds according to the camera manufacturer. Using this setup, the combined camera-oscilloscope acquisition during any part of the process such as erosion beginning or the steady state erosion condition is realised.

Sub-routines are programmed using MATLAB in order to correlate the images and electrical signals of each spark as shown in Fig. 4. Sparks can be characterised as good sparks, arcs and short sparks based on their electrical signals and set threshold values. Sparks with discharge voltage below 8 V are considered the short sparks. Sparks with low open voltage or very short delay time are characterised as arcs. Sparks with an open voltage above $80 \%$ programmed ignition voltage, i.e. $80 \mathrm{~V}$ and a minimum delay time of $1 \mu$ s are characterised as good sparks. Only good sparks are considered in this work, and the other spark types are omitted from statistical analysis. 
Fig. 4 Left: image of a spark (75 $\mu$ s duration, $20 \mathrm{~A}$ ) and its voltage and current signals, sorted from the acquired cameraoscilloscope data using the MATLAB sub-routines. Right: method of spark characterisation based on voltage and current thresholds
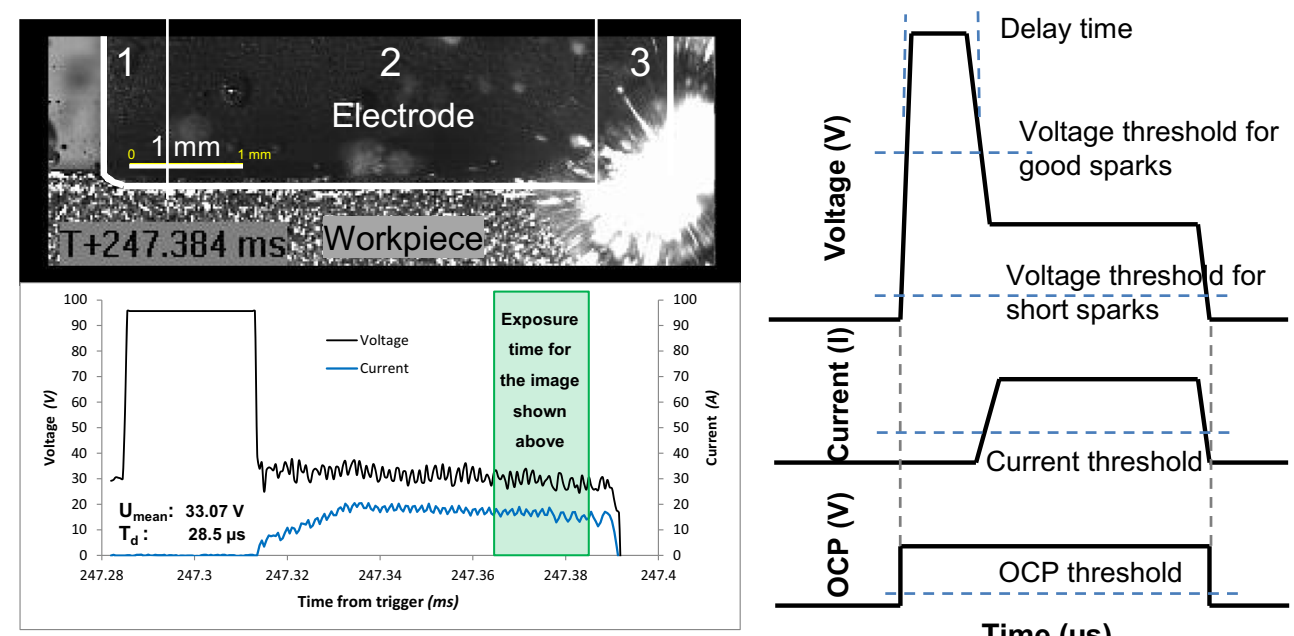

Time ( $\mu \mathrm{s})$
Once all the sparks from the acquired data are characterised, mean discharge voltage $U_{\mathrm{e}}$ and delay time $T_{\mathrm{d}}$ of each detected good spark are calculated. Here, the time between the generator control pulse (OCP) rising edge and the current signal rising edge is considered as discharge delay time $T_{\mathrm{d}}$. For the mean discharge voltage $U_{\mathrm{e}}$ calculation, the acquired voltage values are averaged after $5 \mu$ s from the rising edge of the current, till the falling edge of the current. Different regions on an electrode are user defined, e.g. corner regions 1, 3 and frontal region 2 of an electrode as shown in Fig. 4. Once all the detected good sparks are assigned to a region in which they occurred, for each defined region, histograms of the spark characteristics, namely mean discharge voltage $U_{\mathrm{e}}$ and delay time $T_{\mathrm{d}}$, are generated.

Fig. 5 Mean discharge voltage $U_{\mathrm{e}}$ histograms of the sparks occurring in different regions of a micro-rib electrode. Defined regions of the electrode are lateral sides (Regions 4, 5), corners (Regions 1,3) and the frontal side (Region 2). Current, 12 A. Here, vertical dashed lines indicate possible threshold values for different regions for the adaptive control as explained in Section 3
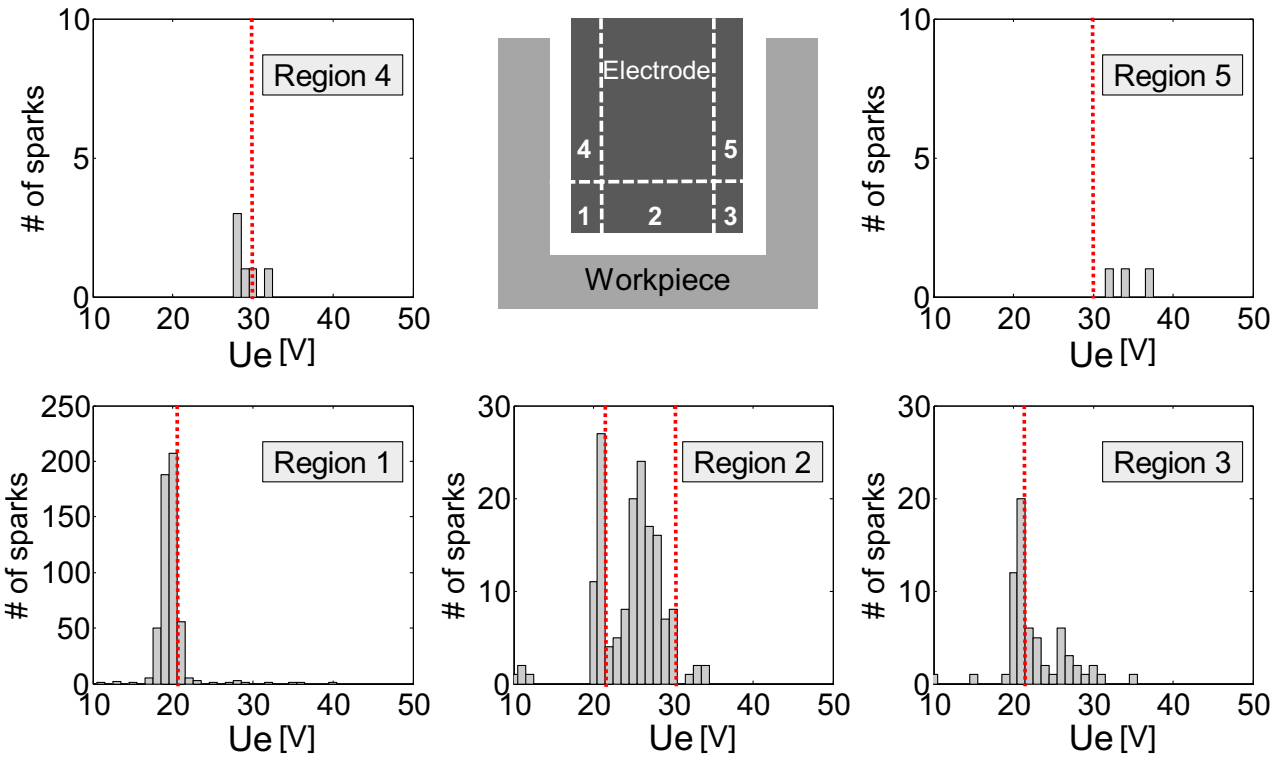
Fig. 6 Discharge delay time $T_{\mathrm{d}}$ histograms of the sparks occurring on different regions of the micro-rib electrode. Defined regions of the electrode are lateral sides (Regions 4, 5), corners (Regions 1,3) and the frontal side (Region 2)
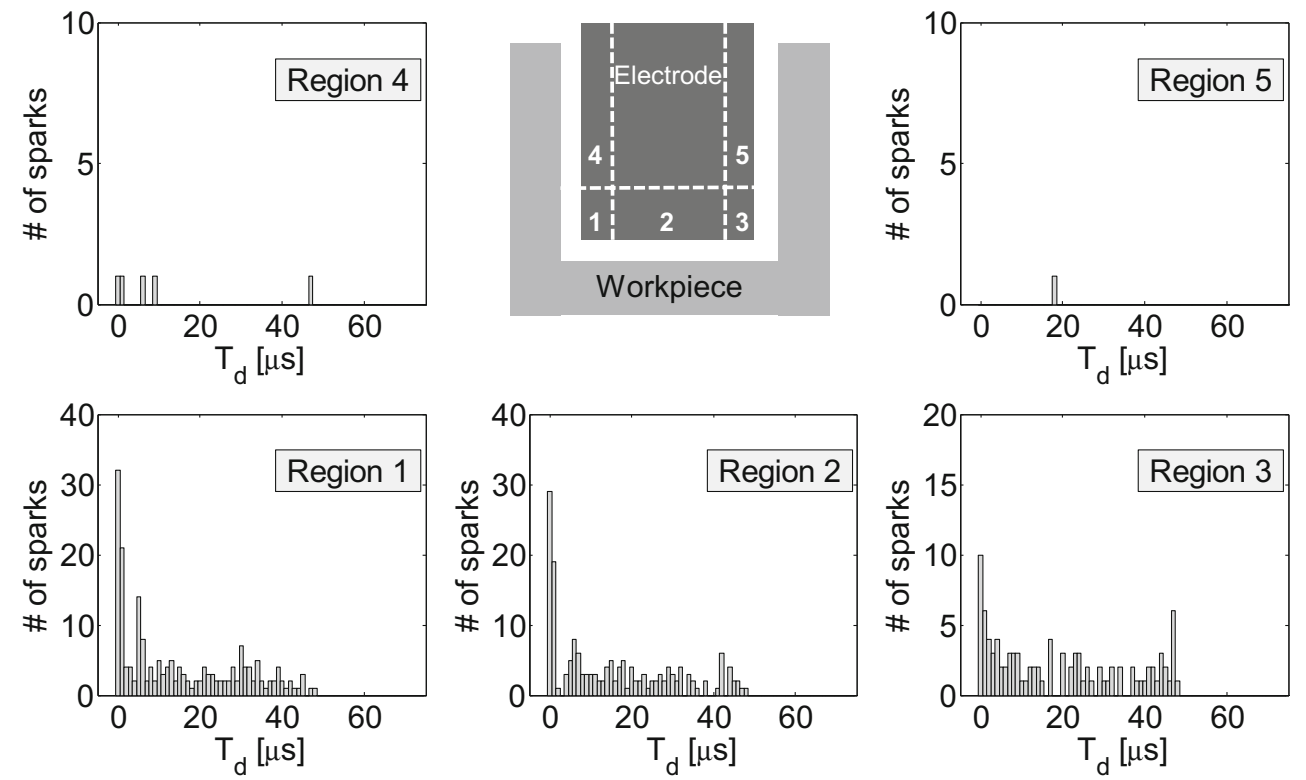

lower gap width on the left side of the electrode may have resulted in a higher number of discharges occurring in region 1. For the sparks occurring on the frontal surface in region 2, the mean $U_{\mathrm{e}}$ is between 22 and $30 \mathrm{~V}$ with a peak around $26 \mathrm{~V}$. Sparks occurring on the lateral sides have a mean discharge voltage $U_{\mathrm{e}}$ near or above $30 \mathrm{~V}$. Since lateral sparks occur on the already eroded surfaces, their occurrence is considerably lower compared to the sparks on the corners and the frontal surface. As opposed to the discharge voltage $U_{\mathrm{e}}$, the discharge delay time $T_{\mathrm{d}}$ and the histograms for the sparks occurring on different regions of the electrode show no visible pattern, as seen in Fig. 6. This behaviour may be caused by the chosen servo control method based on the mean discharge voltage $U_{\mathrm{e}}$ as reference.
A microelectrode with a cross section of $0.25 \mathrm{~mm} \times 0.25 \mathrm{~mm}$ $\left(A_{p} 0.0625 \mathrm{~mm}^{2}\right)$ is used to erode a $0.3 \mathrm{~mm}$ thin steel 1.1274 plate at a depth of $4 \mathrm{~mm}$ in a near-real erosion condition, as shown in Fig. 3b. Figure 7 shows the calculated mean discharge voltage $U_{\mathrm{e}}$ of the sparks occurring on the frontal and lateral regions of the microelectrode. It is seen that most of the sparks occurring on the front region have relatively lower mean discharge voltage $\left(U_{e}<32 \mathrm{~V}\right)$ with a peak around $26 \mathrm{~V}$ compared to the sparks occurring on the lateral sides $\left(U_{e}>32 \mathrm{~V}\right)$.

A combination electrode having a micro-feature with a cross section of $0.5 \mathrm{~mm} \times 0.5 \mathrm{~mm}\left(A_{p} 0.25 \mathrm{~mm}^{2}\right)$ and a mesoscale feature with $3 \mathrm{~mm} \times 3 \mathrm{~mm}$ cross section $\left(A_{p} 9 \mathrm{~mm}^{2}\right)$ is used to erode steel plates (thickness $0.6 \mathrm{~mm}, 3.2 \mathrm{~mm}$, respectively) at a depth of $3 \mathrm{~mm}$ as shown in Fig. 3c. The calculated
Fig. 7 Mean discharge voltage $U_{\mathrm{e}}$ histograms of the sparks occurring on different regions of a microelectrode. Defined regions of the electrode are frontal (Region 2) and lateral sides (Region 1). Current, 8 A
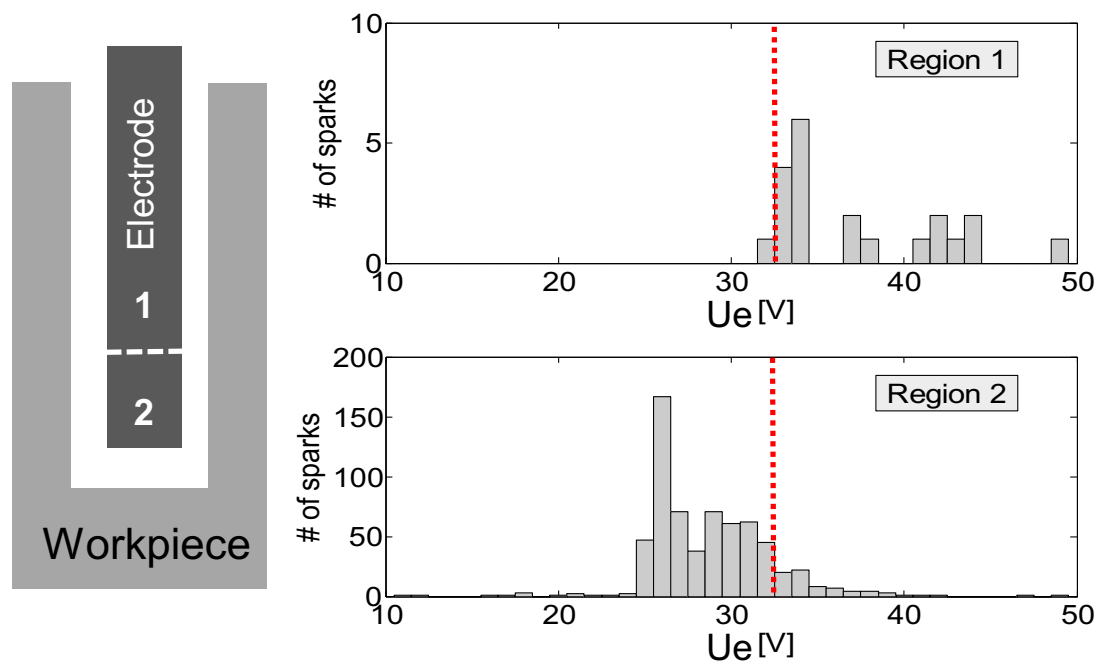
Fig. 8 Mean discharge voltage $U_{\mathrm{e}}$ histograms of sparks occurring on different regions of a combination electrode. Defined regions of the electrode are the micro- (Region 1) and the mesofeature (Region 2). Current, $14 \mathrm{~A}$
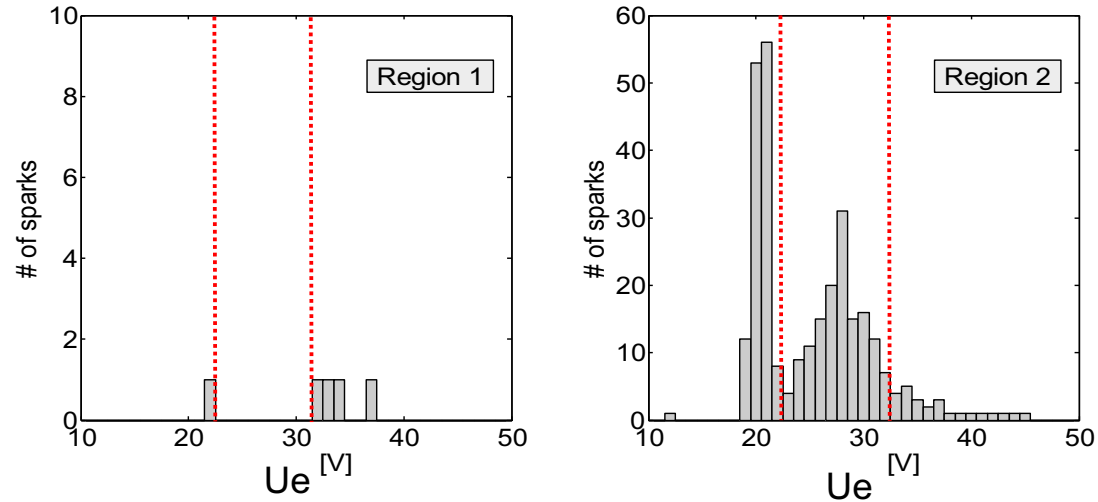

mean discharge voltage $U_{\mathrm{e}}$ of the sparks occurring on the combination electrode shown in Fig. 8 suggests that most of the sparks occurring on the meso-feature have the mean discharge voltage $U_{\mathrm{e}}$ between 20 and $32 \mathrm{~V}$ with a peak around $27 \mathrm{~V}$. The sparks with $U_{\mathrm{e}}$ around $20 \mathrm{~V}$ in the region 2 would indicate the sparks occurring on the corner regions of the mesoscale feature based on the understanding derived from Fig. 5 for the micro-rib electrode. Here, most of the observed sparks on the micro-feature of the electrode were on the lateral sides with $U_{e}>32 \mathrm{~V}$ (region 1). Since the mesoscale feature has a much larger electrode projection area compared to the microscale feature, a higher number of sparks occurred in region 2 for the analysed video duration of $1.4 \mathrm{~s}$.

Based on the statistical analysis presented above, one may define at least two distinct voltage threshold values, namely Ref1 and Ref2 as shown in Fig. 9. The sparks with mean discharge voltage $U_{\mathrm{e}}$ higher than the Ref1 value (e.g. $32 \mathrm{~V}$ ) are considered as lateral or unstable discharges. The sparks with mean discharge voltage $U_{\mathrm{e}}$ lower than the Ref2 value (e.g. $22 \mathrm{~V}$ ) are considered to have occurred on the microscale

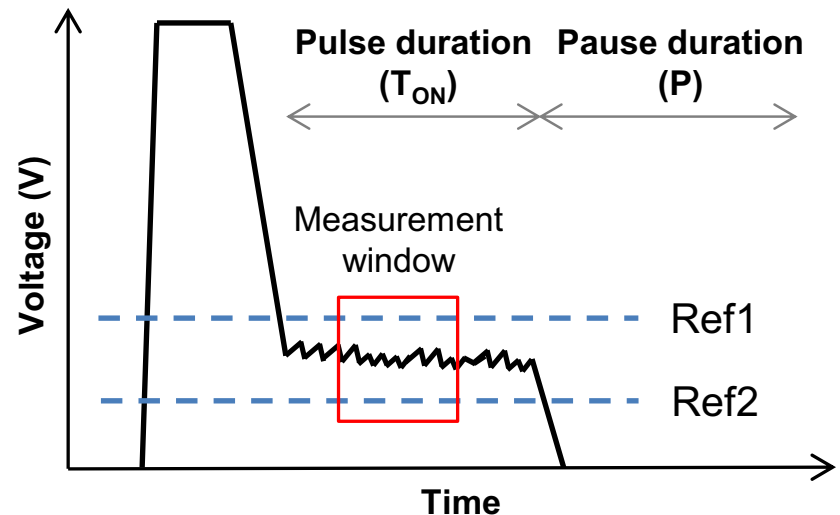

Fig. 9 Determination of the spark location based on the measured discharge voltage $U_{\mathrm{e}}$ and comparison with the defined threshold levels Ref 1 and Ref 2 . The sparks with $U_{\mathrm{e}}>\operatorname{Refl}$ are considered as the lateral sparks, and the sparks with $U_{\mathrm{e}}<\operatorname{Ref} 2$ are considered to be occurring on the microscale regions of the electrode electrode features, including corners and edges of the electrodes. The sparks with a mean discharge voltage between these two defined levels $(\operatorname{Ref} 1,2)$ are considered to be occurring on the macro- and mesoscale surfaces.

\subsection{Underlying mechanism}

In order to clarify the dependence of discharge voltage/current on the spark location, Valentinčič and Junkar [12] have proposed a change in the gap width depending on the electrode area. It is suggested that the gap width must be lower for microscale areas compared to the frontal surfaces. For lower gaps, the length of the plasma channel would be shorter,

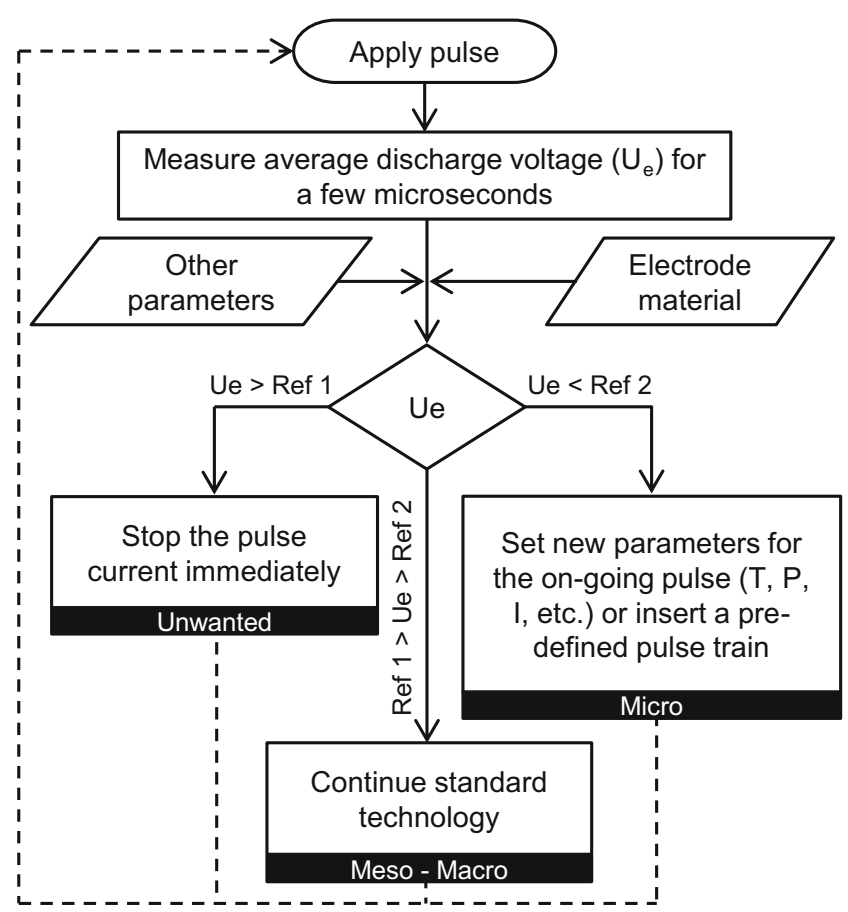

Fig. 10 Flow chart of the spark location adaptive process control based on the measured discharge voltage $U_{\mathrm{e}}$ of each spark 

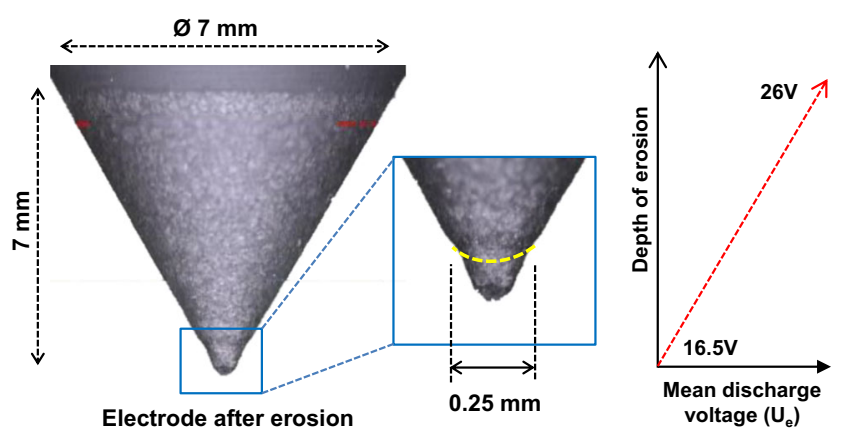

Fig. 11 Example of a conical graphite electrode with carbonaceous build-up on the apex after erosion using the adaptive control (Ref2 $20 \mathrm{~V}$ ) with $20 \mathrm{~A}$

leading to a lower measured discharge voltage. This is however only true if the plasma channel resistivity is assumed to be constant. It is known that the gaseous plasma state has different voltage than the metal plasma state as shown by $[22,23]$. Thus, for the same gap width, different electrical resistivity of the plasma channel may also cause a change in the measured discharge voltage.

It is proposed that the metallic or arc type discharges containing high amount of cathode metal vapour occur in the micro-regions since the available amount of dielectric fluid in the vicinity of the discharge region is limited. On the other hand, gaseous discharges occur from the continual dielectric breakdown on the macro-regions of the electrode. For longer pulse durations, the metal vapour density increases in these discharges surrounded by a large gas bubble. This hypothesis has been validated by [2], where light emission spectroscopy of discharge plasma is performed during multiple discharge process in near-real erosion conditions. It is found that the portion of metallic vapour increases in the discharge plasma and the mean discharge voltage decreases when the electrode projection area becomes smaller. Also, a similar observation has been made by [24], where the metallic content of the plasma is found to be increasing with the erosion depth for microscale electrodes, where most of the discharges occur inside gas bubbles. Thus, the probability of metallic discharges is higher in the microscale regions compared to meso-macroscale regions. Vice versa, the probability of gaseous discharges is higher in the macroscale regions.

Apart from static considerations, the dynamic behaviour of plasma with time must also be considered. For longer pulse durations, the gaseous phase discharges eventually transit to the metallic and arc phase discharges. For the microscale areas, this transition may occur within $20 \mu$ s from the breakdown, whereas for the macroscale areas, it may take longer than $150 \mu \mathrm{s}$. The transition times may depend on the used materials, current and electrode geometry. Thus, gap width and plasma state may influence the discharge voltage and give information of the spark location on the electrode. In order to predict the discharge voltage, one must consider the voltage drop across the electrode and workpiece, which is marginal for metals, except for the very thin or long electrodes. The voltage drop across the plasma channel is defined by the plasma resistivity and thus on the plasma channel radius and length.

\section{Adaptive process control}

\subsection{Method and algorithm}

In a simple form, an adaptive control for changing the process parameters based on the spark location can be conceptualised using two voltage threshold levels as shown in Fig. 9. Here, by measuring the mean discharge voltage of each spark, one may adapt the process technology parameters such as pulse duration and pause duration as shown in Fig. 10. Once the probabilistic spark location on a specific electrode region is attributed, the process technology for the considered spark can be changed within a few microseconds $(<10 \mu \mathrm{s})$ through the field-programmable gate array (FPGA) control. If required, also the parameters of subsequent sparks may be changed. The voltage threshold values and the process parameters mainly depend on the electrode geometry, materials and
Fig. 12 Corner form of the eroded cavities using $4.62 \mathrm{~mm}$ diameter electrodes with $20 \mathrm{~A}$. Settings when using the graphite electrodes: (1) Ref2 $26 \mathrm{~V}, T_{\mathrm{ON}}$ $20 \mu \mathrm{s} ;$ (2) Ref2 $24 \mathrm{~V}, T_{\mathrm{ON}} 20 \mu \mathrm{s}$; (3) Ref2 $22 \mathrm{~V}, T_{\mathrm{ON}} 130 \mu \mathrm{s}$. Settings for the copper electrodes: (1) Ref2 $18 \mathrm{~V}, T_{\mathrm{ON}} 20 \mu \mathrm{s}$; (2) Ref2 $22 \mathrm{~V}, T_{\mathrm{ON}} 154 \mu \mathrm{s}$; (3) Ref2 $24 \mathrm{~V}, T_{\mathrm{ON}} 274 \mu \mathrm{s}$
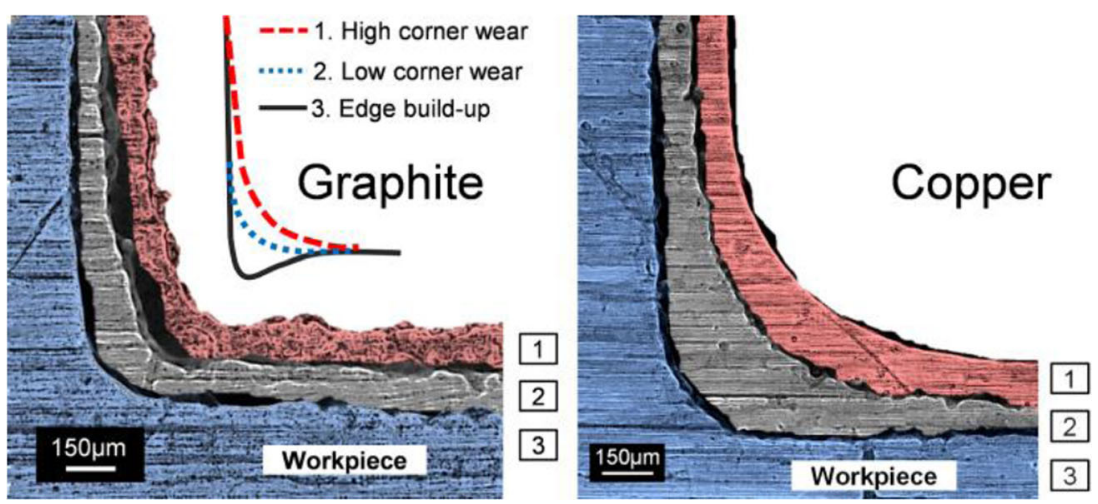
Fig. 13 Comparison of the standard adaptive control and the spark location-based control to adapt the process parameters of sparks occurring on the microregions. The graphite electrode with macro- to microscale features is used for erosion using $20 \mathrm{~A}$
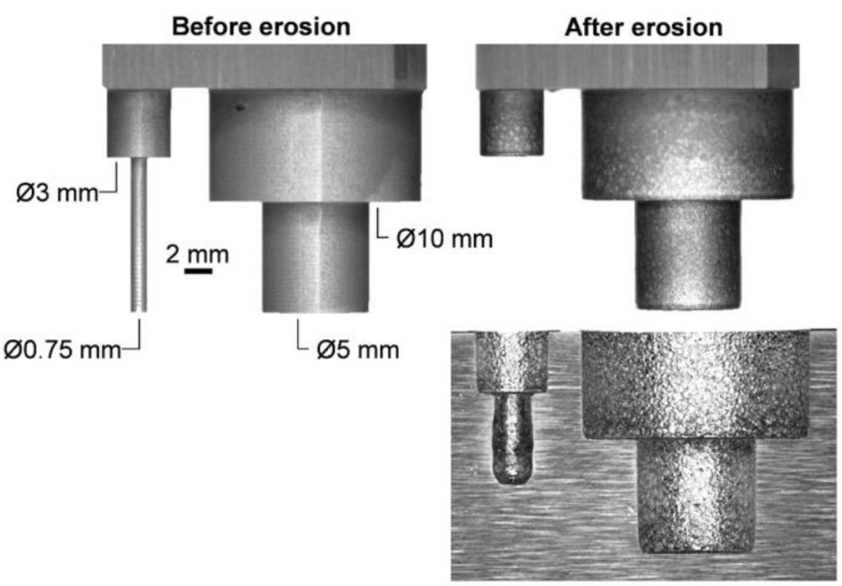

Standard technology
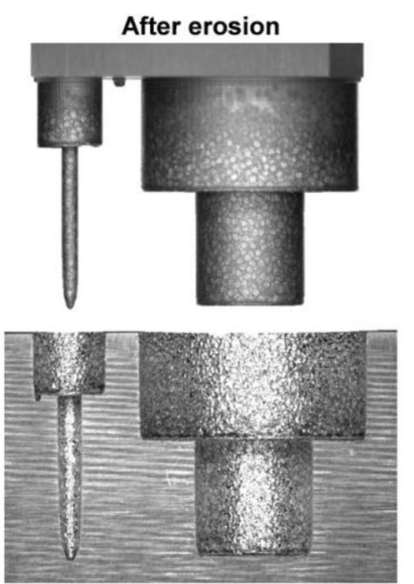

Control for sparks on micro regions applied current. Since the corrective actions required for the sparks occurring on microscale features and on lateral sides may be different, the effect of controls based on Ref2 (microregions) and Ref1 (lateral sides) are analysed separately, followed by an example of combined adaptive control using both the Ref1- and Ref2-based control.

\subsection{Sparks on the micro-features}

The micro-features on an electrode incur high wear when subject to high average current and short pulse durations, both for graphite and copper electrodes. In order to achieve low wear, long pulse durations and low average current are required as seen from Maradia et al. [25]. Thus, for the sparks detected on the micro-features based on Ref2 threshold, longer pulse durations followed by longer pause durations are used by the adaptive control.

Since a conical electrode has varying surface area with increasing depth of erosion, a conical electrode as shown in Fig. 11 is used for erosion of steel 1.2343 using the proposed spark location adaptive control with 20 A. Since the spark

Table 2 Process output results for microerosion with and without the lateral spark adaptive control for the graphite and copper microelectrodes

\begin{tabular}{lllllll}
\hline Current (I) & & \multicolumn{3}{c}{ Graphite } & & \multicolumn{2}{l}{ Copper } \\
\cline { 3 - 4 } \cline { 6 - 7 } & & $20 \mathrm{~A}$ & $20 \mathrm{~A}$ & & $20 \mathrm{~A}$ & $20 \mathrm{~A}$ \\
\hline Ref 1 & $(\mathrm{V})$ & No kill & 32 & & No kill & 30 \\
Mean side gap & $(\mathrm{mm})$ & 0.320 & 0.235 & & 0.425 & 0.310 \\
Erosion time & $(\mathrm{min})$ & 255 & 222 & & 192 & 213 \\
Frontal wear & $(\mathrm{mm})$ & -0.094 & -0.240 & & 0.316 & 0.159
\end{tabular}

Here, negative wear values indicate a carbonaceous build-up on the electrode front breakdown is of stochastic nature, a spark could occur on a larger surface of the cone, and the subsequent spark may occur on the apex of the cone. The measurement of discharge voltage at $1 \mathrm{~ms}$ interval performed during the erosion shows a beginning value of $16.5 \mathrm{~V}$ (at electrode tip), steadily increasing to $26 \mathrm{~V}$ (at $7 \mathrm{~mm}$ diameter) with increasing depth of erosion and thus increasing electrode projection area. Thus, depending on the location of a spark ranging from the apex point $\left(U_{\mathrm{e}} 16.5 \mathrm{~V}\right)$ to the largest diameter of $7 \mathrm{~mm}\left(U_{\mathrm{e}} 26 \mathrm{~V}\right)$, the pulse parameters are modified. The input for the process control are $20 \mathrm{~V}$ for Ref 2 and the measurement window of $20 \mu$ s duration, beginning after $20 \mu$ s from the discharge breakdown. If the mean discharge voltage $U_{\mathrm{e}}$ is found to be below $20 \mathrm{~V}$, pause duration of $1 \mathrm{~ms}$ is added at the end of the considered discharge. Thus, whenever the spark occurs in the peak region of the electrode, the average current is reduced by increasing the pause duration. The electrode after erosion shows the build-up of a peak with a nose radius smaller than $0.25 \mathrm{~mm}$, with no frontal wear. Although similar experiments have been reported through the surface area adaptive control by Valentincic et al. [13], the

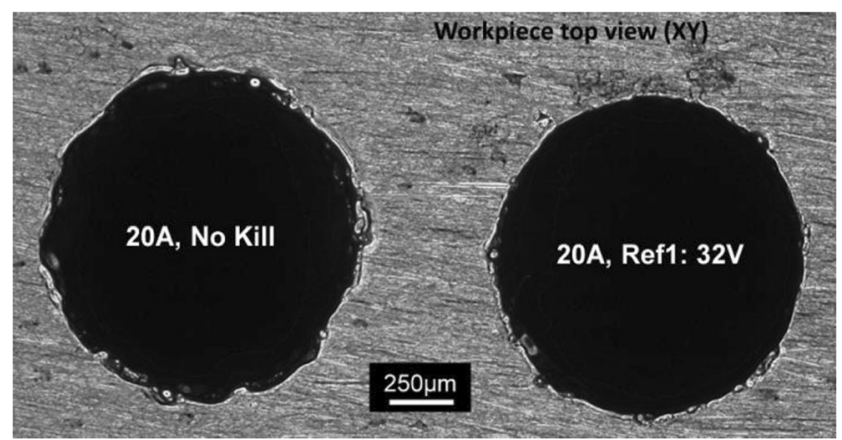

Fig. 14 Top view of the cylindrical eroded cavities without (left) and with (right) lateral sparks suppression (kill). The graphite electrode diameter is $0.9 \mathrm{~mm}$, and the depth of erosion is $9 \mathrm{~mm}$. For the erosion, 20 A with a pulse duration of $154 \mu$ s is used 


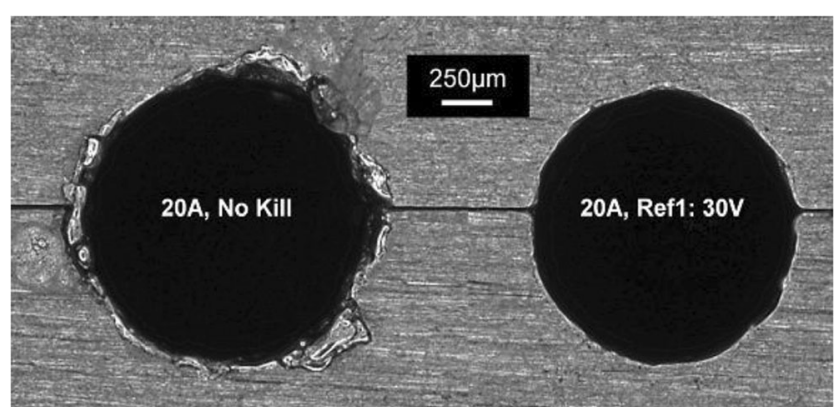

Fig. 15 Top view of the cylindrical eroded cavities without (left) and with (right) lateral sparks suppression (kill). The copper electrode diameter is $1 \mathrm{~mm}$, and the depth of erosion is $10 \mathrm{~mm}$. For the erosion, 20 A with pulse duration of $316 \mu$ s is used

presented spark location adaptive control offers higher precision through the regulation of pulse parameter of each spark, during the spark duration itself.

The effect of adaptive control on corners and edges of the eroded cavities is analysed for erosion using $20 \mathrm{~A}$ with $\varnothing 4.62 \mathrm{~mm}$ graphite and copper electrodes. As shown in Fig. 12, the pulse durations for sparks occurring on the edges of the macroelectrode are changed. For the graphite electrodes, the shortest pulse duration of $20 \mu$ s (example 1) results in high corner wear, compared to the longest pulse duration of $130 \mu \mathrm{s}$ resulting in a carbonaceous build-up on the electrode edges. For the copper electrode, a similar behaviour is observed, where the longest pulse duration of $274 \mu$ s (example 3) results in low corner wear.

The capability of the proposed process control to adapt with the different surface areas of the electrode in the same plane and along the erosion depth is analysed by eroding macro- $\left(A_{\mathrm{p}}>\right.$ $\left.10 \mathrm{~mm}^{2}\right)$, meso- $\left(A_{\mathrm{p}} 10 \mathrm{~mm}^{2}-1 \mathrm{~mm}^{2}\right)$ and micro- $\left(A_{\mathrm{p}}<1 \mathrm{~mm}^{2}\right)$ scale surfaces on a single electrode. The electrode dimensions are shown in Fig. 13, where two erosion process control strategies, namely standard adaptive control from the EDM machine and the spark location adaptive control have been compared for $10 \mathrm{~mm}$ deep erosion using $20 \mathrm{~A}$. The standard adaptive control from the machine manufacturer uses various ACCs and ACOs in order to improve the process as summarised by [19], such as stopping abnormal discharges, flushing jump interval time, etc.
For the spark location adaptive control, the standard machine adaptive controls are deactivated, and only the proposed control based on the voltage threshold value Ref2 in addition to the machine gap control is used. The threshold value Ref2 is determined by the peak around $22 \mathrm{~V}$ in Fig. 8. Thus, the average current applied on the microscale features is reduced by increasing the pause duration to $1000 \mu \mathrm{s}$ when a spark is detected on the micro-region $\left(U_{\mathrm{e}}<22 \mathrm{~V}\right)$. After roughing, the frontal wear of the macro-mesoscale surfaces is below $10 \mu \mathrm{m}$ for both process control methods. However, the microscale feature $\left(A_{\mathrm{p}}\right.$ $0.44 \mathrm{~mm}^{2}$ ) is broken during the erosion with the standard technology control. This is because a high average current is applied by the standard control also on the microscale feature. This results in process instability leading to a large overcut and eventual a breakage of the microelectrode. On the other hand, the micro-feature has $0.245 \mathrm{~mm}$ frontal build-up in form of a tip when using the spark location adaptive control. Here, lateral wear on the microscale feature results in a conical shape at the tip. The erosion time for the standard adaptive control is $192 \mathrm{~min}$, and for the spark location, adaptive control is $200 \mathrm{~min}$.

\subsection{Sparks on the lateral surfaces}

The sparks occurring on lateral or side surfaces increase the overcut of the eroded cavity. Also, lateral forces on the electrode may affect the process stability for high aspect ratio electrodes reducing the achievable precision. Since the lateral sparks are mostly undesirable, the presumed lateral sparks with $U_{\mathrm{e}}$ above the defined Refl are terminated or killed upon their detection within a few microseconds.

The capability of the adaptive control to suppress lateral sparks is analysed for erosion using microscale electrodes. With $\varnothing 0.9 \mathrm{~mm}$ graphite electrodes, $9 \mathrm{~mm}$ deep cavities are eroded in steel 1.2343 using $20 \mathrm{~A}, 154 \mu$ s pulse duration and $1000 \mu$ s of pause duration. A comparison of the process outputs for erosion using 20 A with Refl set to $32 \mathrm{~V}$ and without adaptive control is presented in Table 2. It can be seen that the lateral spark suppression algorithm with the set Ref1 results in $26 \%$ lower side gap from 0.32 to $0.235 \mathrm{~mm}$. At the same time, the erosion time is decreased by $13 \%$
Fig. 16 Comparison of surface burrs and form precision produced on the initial zero-plane of the cavities eroded using $\varnothing 1 \mathrm{~mm}$ copper electrodes. The current is $20 \mathrm{~A}$, and the pulse duration is $316 \mu$ s. Left: no adaptive control; Right: Spark location adaptive control with Ref1 set to $30 \mathrm{~V}$
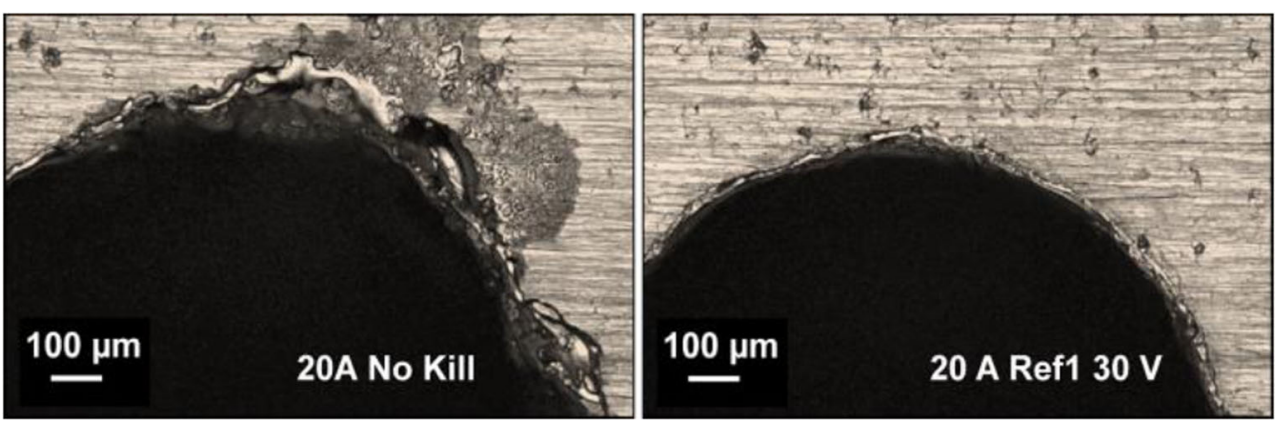
Fig. 17 Comparison of the lateral surface topography of the eroded micro-cavities without (left) and with (right) adaptive control. It can be seen that much larger craters and microcracks are generated without the proposed adaptive process control. The applied current is $20 \mathrm{~A}$, pulse duration $154 \mu$ s and Ref1 set to $32 \mathrm{~V}$ for a $\varnothing 0.9 \mathrm{~mm}$ graphite electrode and $9 \mathrm{~mm}$ depth of erosion in steel 1.2343

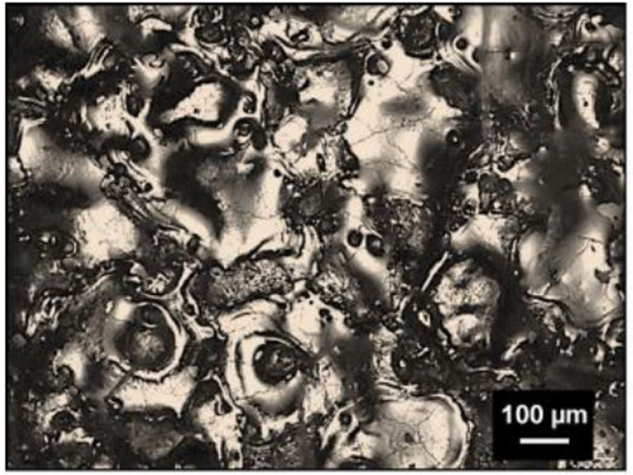

20A No Kill

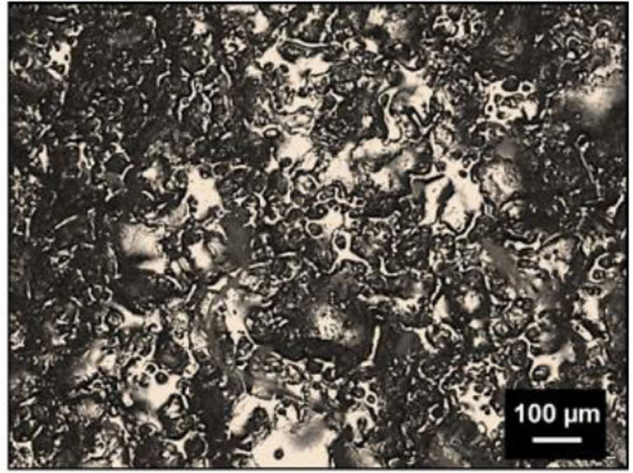

20A 32V Kill from 255 to $222 \mathrm{~min}$. On the other hand, erosion of a $10 \mathrm{~mm}$ deep cavity using a $\varnothing 1 \mathrm{~mm}$ copper electrode is performed with $20 \mathrm{~A}$ and $316 \mu$ s pulse duration. For Ref1 set to $30 \mathrm{~V}$, the side gap is reduced by $27 \%$, whereas the frontal wear is reduced by about $50 \%$. A slight increase in the erosion time is observed when using the copper microelectrodes. Figures 14 and 15 show the top view of the eroded cavities using graphite and copper microelectrodes, respectively. It can be seen that the cavities produced using the adaptive control (right) have better form accuracy. Also, the reduction of surface burrs is visible, especially in case of erosion using the copper electrode as shown in Fig. 16.
Apart from the form accuracy, the surface quality of the eroded lateral surfaces is also improved, especially when using the graphite electrodes shown in Fig. 17. Since the discharge durations of the lateral sparks is reduced to 20-30 $\mu \mathrm{s}$ from $154 \mu \mathrm{s}$ by the adaptive control, the surface quality resulting from lateral spark suppression is expected to be similar to that of the shorter pulse durations. Also, as shown in Fig. 18, the re-solidified layer (seen as black region) is reduced on the lateral surfaces when using the lateral spark suppression. Additionally, sharp corners in the entry region of the cavity and a better shape are observable for the cavity eroded using the adaptive control. Similar results have been achieved
Fig. 18 Comparison of form accuracy, surface and sub-surface quality of the $9 \mathrm{~mm}$ deep eroded cavities using $\varnothing 0.9 \mathrm{~mm}$ graphite electrodes with (Ref1 $32 \mathrm{~V}$ ) and without (no kill) lateral spark adaptive process control

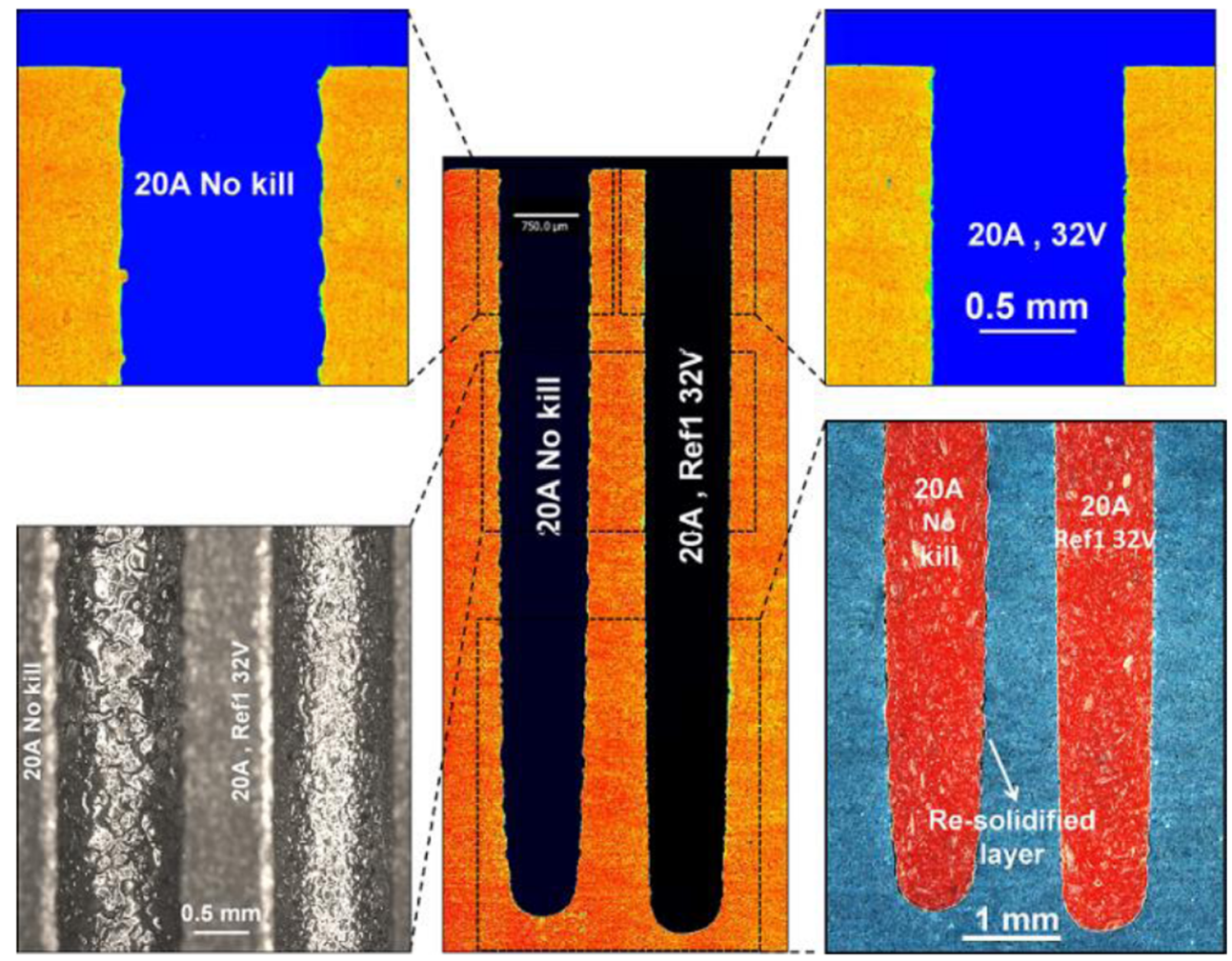


Fig. 19 Comparison of form accuracy, surface and sub-surface quality of the $10 \mathrm{~mm}$ deep eroded cavities using $\varnothing 1 \mathrm{~mm}$ copper electrodes with (Ref1 $30 \mathrm{~V})$ and without (no kill) lateral spark adaptive process control
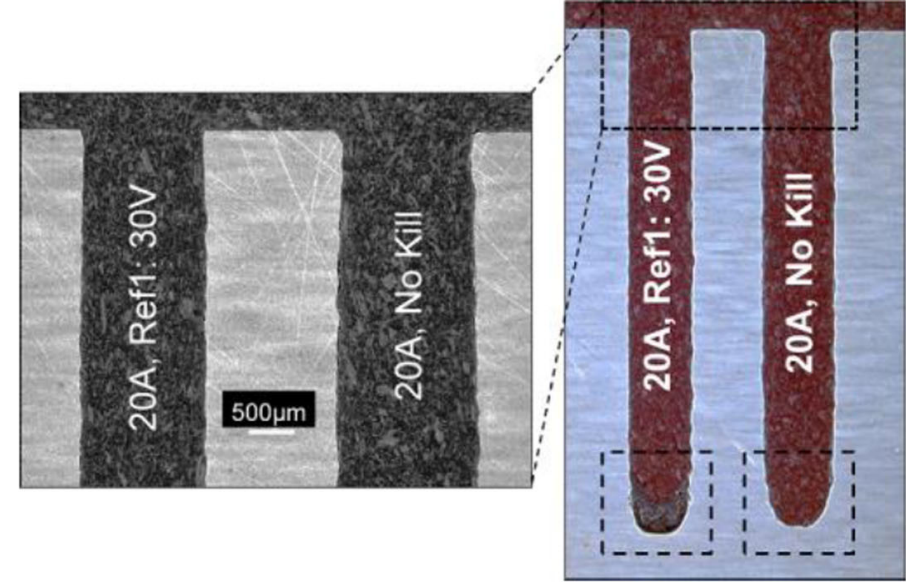
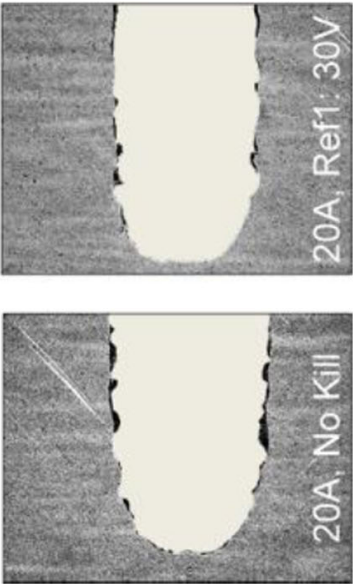

when using $\varnothing 1 \mathrm{~mm}$ copper electrodes for the erosion with $20 \mathrm{~A}$, as shown in Fig. 19. It can be seen that whilst the sharp edges are achieved on the initial workpiece surface, the eroded cavity without lateral spark suppression has a negative taper.

Whilst the micro- or high aspect ratio electrodes incur vibrations from the machine itself, the vibrations from the discharge process are also considerable. Forces applied by lateral discharges cause deflections of the electrode. This leads to a cycle of short or lateral sparks on the lateral surfaces, causing lateral wear and conical shape of the microelectrodes. In some cases, this may lead to a breakage of the graphite electrodes. However, with the proposed lateral spark suppression method, one may stop the lateral sparks within a few microseconds, thus reduce discharge forces on the electrode and its deflection. The graphite and copper electrodes used for the erosion tests are shown in Figs. 20 and 21, respectively. Without the adaptive control, a conical shape of the graphite electrode results due to lateral wear. However, when the spark location adaptive control with Refl set to $32 \mathrm{~V}$ for $20 \mathrm{~A}$ is used, a negligible lateral wear occurs. A higher form accuracy of the eroded cavity is also attributed to the near-zero lateral wear of the electrode. Owing to the smaller side gap and lower surface roughness, one may infer that the lateral discharges causing

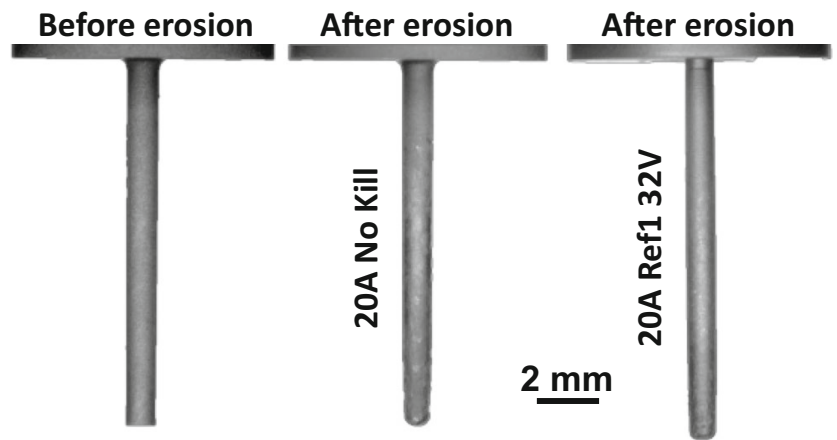

Fig. 20 The effect of erosion using the adaptive control (Ref2) on $\varnothing 0.9 \mathrm{~mm}$ graphite electrodes. The lateral spark suppression (right) results in a lower lateral and corner wear of the electrode the electrode vibration and lateral wear are efficiently restrained using the proposed adaptive control.

\subsection{Demonstration of combined control}

In order to summarise the effect of the spark location adaptive control based on both Ref1 and Ref2, a combination electrode having macro- to microscale features as shown in Fig. 13 is used for erosion in steel 1.2343. The adaptive control is used only for roughing with $20 \mathrm{~A}$ using the first electrode. Here, pause duration of $2000 \mu \mathrm{s}$ is added for the sparks occurring on the microscale surfaces including the edges and corners when the discharge voltage $U_{\mathrm{e}}$ is below Ref2 set to $22 \mathrm{~V}$. Additionally, the sparks occurring on the lateral sides with discharge voltage $U_{\mathrm{e}}$ above $32 \mathrm{~V}$ are stopped immediately upon detec-

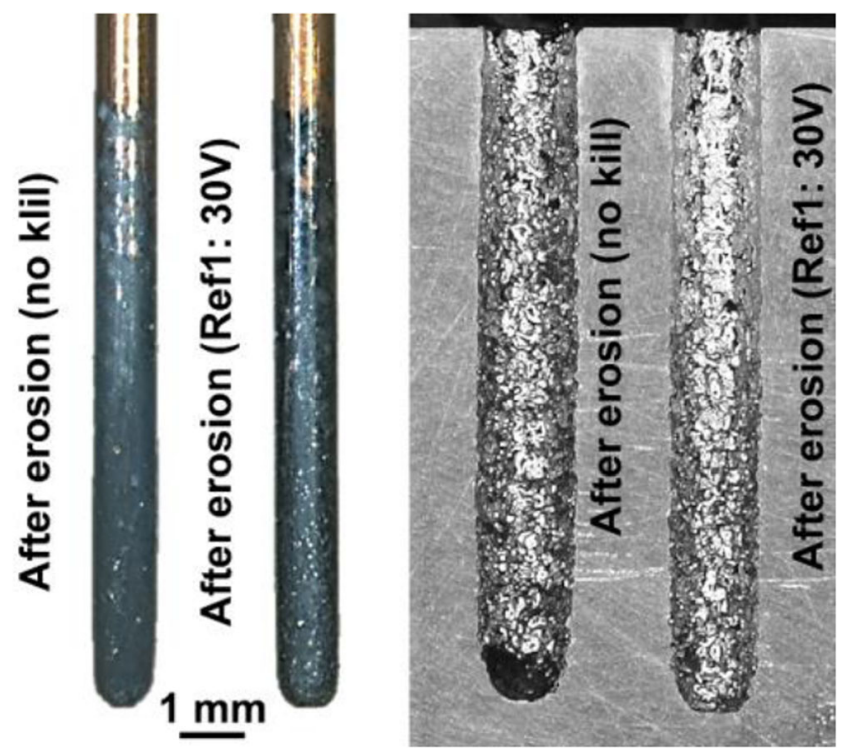

Fig. 21 The effect of lateral spark suppression resulting in lower lateral and corner wear of $\varnothing 1 \mathrm{~mm}$ copper electrodes. A slightly negative taper shape of the eroded cavity (left) in longitudinal direction is observed for the erosion without adaptive control, whereas a cylindrical shape is observed when the adaptive control is used (right) 


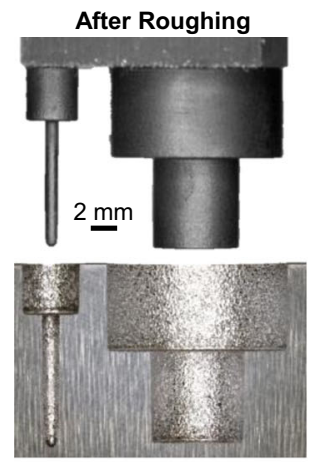

EL 1: Roughing

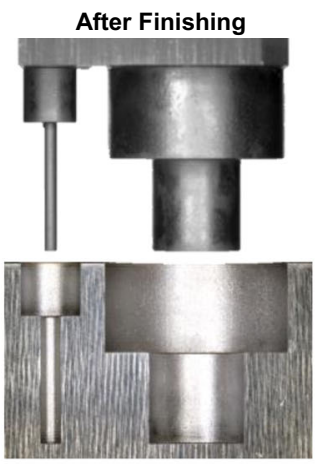

EL 2: Finishing

Fig. 22 Erosion of a cavity with macro- to microscale features using the spark location adaptive control. Here, parameters of the sparks occurring on the microscale features and the lateral sides are adapted to achieve low

tion within a few microseconds. The achieved results are shown in Fig. 22. It is seen that near-zero frontal and lateral wear is achieved during the erosion with $20 \mathrm{~A}$. The high shape accuracy due to a near-zero wear during roughing results in low wear for the finishing operation using a second electrode. The surface roughness $R_{\mathrm{a}}$ of the final cavity is about $0.25 \mu \mathrm{m}$, measured using a surface profiler, Talysurf from Taylor Hobson. The shape accuracy of the final machined cavity using two electrodes is shown in Fig. 22, where inner corner radii of $140 \mu \mathrm{m} \pm 5 \mu \mathrm{m}$ and $0.4 \mathrm{~mm}$ oversize of the cavities are achieved for $10 \mathrm{~mm}$ erosion depth. A total erosion time of $383 \mathrm{~min}$ is required to machine the final cavity, where $163 \mathrm{~min}$ required for roughing using the spark location adaptive control is $30 \mathrm{~min}$ less than the erosion using the standard adaptive control. Results are shown in Fig. 13.

\section{Conclusions}

A novel method using high-speed imaging is developed to characterise EDM sparks based on their geometric location on the electrode under near-real erosion conditions. The method allows the process observation using conventional electrode materials in steady state conditions. From the timesynchronised analysis of spark locations on the electrode and the corresponding electrical signals, the dependence of mean discharge voltage $U_{\mathrm{e}}$ /current (based on the generator type) of a spark on its geometric location on the electrode is established. The sparks occurring on micro-regions are found to have lower discharge voltage compared to the frontal region of an electrode. The sparks on lateral sides of an electrode have even higher discharge voltage than the ones on the frontal area. This effect is assumed to be caused by changes in the gap width and the discharge plasma state for the local curvature shapes. Whilst currently the mean discharge voltage values of sparks in different electrode regions are determined experimentally, a model of plasma channel and probabilistic estimation of gas bubble dynamics in the discharge region

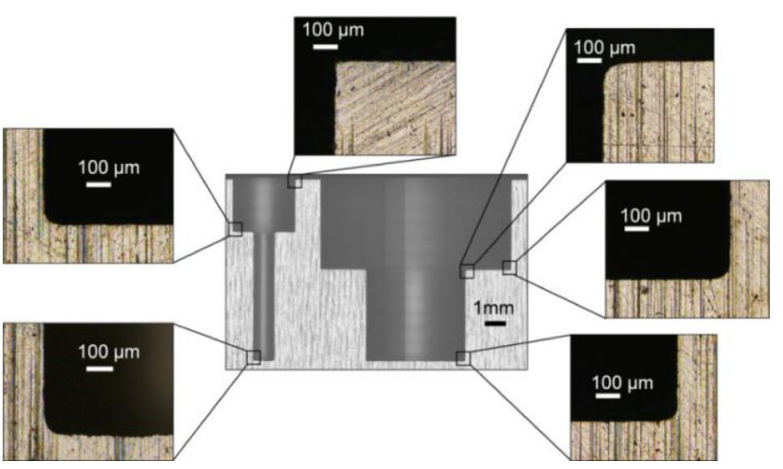

wear and lower erosion times. The final form of the machined cavity after roughing and finishing using two combination electrodes is also shown

may enable prediction of the discharge voltage values of sparks in different geometric regions.

Based on the understanding, a spark location-based adaptive control is conceptualised, where the process parameters can be changed using FPGA control for each spark at microsecond scale, which is unique amongst the known metal machining processes. The adaptive control enables shaping of corners or edges of the macro-mesoscale electrodes to achieve smaller inner corner radii in the machined cavities. Additionally, suppression of the lateral sparks using the adaptive control results in lower side gaps, lower surface roughness, smaller re-solidified layer and lower surface burrs. Also, electrode vibrations and the process instability caused by lateral sparks are reduced, resulting in higher shape accuracy and near-zero lateral wear.

For an example of erosion of precision cavities using combination electrodes having macro- to microscale features, the capabilities of the proposed spark location adaptive control are demonstrated. The application of this control results in low- or near-zero tool wear, thus reducing the required number of electrodes to reach the desired shape accuracy and the geometric errors induced by the electrode change. Reduction in the required number of electrodes to machine macro- to microscale high precision structures increases economic and energy efficiency of the precision die-sinking EDM process.

Acknowledgments The authors wish to acknowledge the financial support by the Swiss Commission for Technology and Innovation (CTI). The authors would also like to thank Mr. J. Boos at inspire AG for machining the electrodes. Contributions from Mr. H. Stark (IWF) and Ms. B. Wegmann (LMPT) of ETH Zurich are acknowledged.

\section{References}

1. Tricarico C, Delpretti R, Dauw D (1988) Geometrical simulation of the EDM die-sinking process. CIRP Ann Manuf Technol 37(1):191-196 
2. Maradia U, Wegener K, Boccadoro M, Knaak R, Stirnimann J Investigation of the scaling effects in meso-micro EDM. In: Proceedings of the ASME 2013 International Mechanical Engineering Congress and Exposition, San Diego, USA, 2013. Americal Society of Mechanical Engineers, pp V02BT02A038V002BT002A038

3. Han F, Kunieda M (2001) Chaos found in distribution of EDM spark. In: Proceedings of the 13th International Symposium on Electromachining ISEM XIII. pp 185-192

4. Inoue K (1970) Constant current density EDM system capable of automatically responding to changing machining area. USA Patent 3:536-881

5. Inoue K (1981) Cutting area responsive EDM method and apparatus with cyclically interrupted pulse trains. USA Patent 4:288-675

6. Toshiaki T (1990) Electric discharge machining method and device. USA Patent 4945199

7. Magara T (1992) Electric discharge machine. USA Patent 5118915

8. Li Y, Zhao W, Feng X, Wei H (1997) Research advancement on online detection of EDM spark locations. Measurement 22(1-2):2935. doi:10.1016/s0263-2241(97)00059-6

9. Kunieda M, Takanobu N (1998) Factors determining discharge location in EDM. Int J Electr Mach 3:53-58

10. Morimoto K, Kunieda M (2009) Sinking EDM simulation by determining discharge locations based on discharge delay time. CIRP Ann Manuf Technol 58(1):221-224. doi:10. 1016/j.cirp.2009.03.069

11. Valentinčič J, Junkar M (2004) A model for detection of the eroding surface based on discharge parameters. Int J Mach Tools Manuf 44(2-3):175-181

12. Valentinčič J, Junkar M (2004) On-line selection of rough machining parameters. J Mater Process Technol 149(1-3):256-262. doi: 10.1016/j.jmatprotec.2003.11.059

13. Valentinčič J, Kuser D, Smrkolj S, Junkar M (2005) Selection of optimal EDM machining parameters for the given machining surface. Paper presented at the 8th International Conference on Management of Innovative Technologies, Fiesa, Slovenia
14. Valentinčič J, Filipič B, Junkar M (2009) Machine learning induction of a model for online parameter selection in EDM rough machining. Int J Adv Manuf Technol 41(9-10):865-870. doi:10.1007/ s00170-008-1532-3

15. Kumagai S, Misawa N, Takeda K, Abdukarimov ET (2004) Plasma-applied machining of a narrow and deep hole in a metal using a dielectric-encased wire electrode. Thin Solid Films 457(1):180-185

16. Klocke F, Garzon M, Braun C, Dieckmann J (2013) Analysis of sinking EDM electrode deflection measurements for the manufacturing of high aspect ratio cavities. Procedia CIRP 6:151-156

17. Okada A, Uno Y, Nakazawa M, Yamauchi T (2010) Evaluations of spark distribution and wire vibration in wire EDM by high-speed observation. CIRP Ann Manuf Technol 59(1):231-234

18. Kitamura T, Kunieda M, Abe K (2013) High-speed imaging of EDM gap phenomena using transparent electrodes. Proc Cirp 6(0):314-319. doi:10.1016/j.procir.2013.03.082

19. Snoeys R, Dauw D, Kruth J-P (1983) Survey of adaptive control in electro discharge machining. J Manuf Syst 2(2):147-164

20. Behrens AW, Ginzel J, Bruhns FL (2004) Threshold technology and its application for gap status detection. J Mater Process Technol 149(1-3):310-315. doi:10.1016/j.jmatprotec.2003.10.041

21. Weck M, Dehmer JM (1992) Analysis and adaptive control of EDM sinking process using the ignition delay time and fall time as parameter. CIRP Ann Manuf Technol 41(1):243-246

22. Boddy PJ, Utsumi T (1971) Fluctuation of arc potential caused by metal-vapor diffusion in arcs in air. J Appl Phys 42(9):3369-3373

23. Gray EW (1972) Voltage fluctuations in low-current atmospheric arcs. J Appl Phys 43(11):4573-4575

24. Maradia U, Hollenstein C, Wegener K (2015) Temporal characteristics of the pulsed electric discharges in small gaps filled with hydrocarbon oil. J Phys D Appl Phys 48(5):055202

25. Maradia U, Boccadoro M, Stirnimann J, Kuster F, Wegener K (2015) Electrode wear protection mechanism in meso-microEDM. J Mater Process Technol 223:22-33 